\title{
A importância democrática dos partidos políticos brasileiros e o comportamento do STF frente às ADIs (1989-2017)
}

The democratic importance of Brazilian political parties and the behavior of the Brazilian Federal Supreme Court judicial in relation to the DAUs (1989-2017)

La importancia democrático de los partidos políticos brasileños y el comportamiento de la corte suprema brasileña en el control de la constitucionalidad (1989-2017)

Gabriela Araújo Tabosa de Vasconcelos ${ }^{1}$ José Mário Wanderley Gomes Neto ${ }^{2}$

\section{Resumo}

VASCONCELOS, G. A. T. de; NETO, J. M. W. G. A importância democrática dos partidos políticos brasileiros e o comportamento do STF frente às ADIs (1989-2017). Rev. C\&Trópico, v. 44, $\boldsymbol{n} . \mathbf{1}$, p. 191-216, 2020. DOI: https://doi.org/10.33148/cetropicov44n1(2020)art9

Para compreender a sociedade atual é importante ter em mente uma compreensão histórica acerca do processo evolutivo que esta passou ao longo do tempo. Desde a origem da democracia na Grécia Antiga até a sua forma moderna. A criação do Estado tal qual o conhecemos hoje foi o que possibilitou a implementação de governos representativos, como no caso do Brasil. Ao final da Idade Média e início da Idade Moderna, a diversidade de interesses sociais bem como a maior possibilidade de força popular, propiciou o surgimento dos primeiros partidos políticos. Até a atualidade permanecem como ponte entre os cidadãos e o governo, são, portanto, entidades de representação social na esfera política e que buscam defender os interesses dos grupos ou camadas sociais que os legitimam com o voto. Uma vez que possuem uma imensa relevância para as democracias contemporâneas, é natural que sejam detentores de diversas modalidades de controle político onde atuam, evidentemente, isso também acontece em nosso país. Daí, munidos de legitimidade ativa para propor Ações Diretas de Inconstitucionalidade, os partidos políticos nacionais atuam também junto ao Poder Judiciário na busca pela melhor defesa de seus interesses. A partir disso, foi desenvolvida uma pesquisa quantitativa que fez uso de regressão binária para melhor explicar a forma como o Supremo Tribunal Federal responde as ADIs impetradas pelos partidos e como isso afeta diretamente a legitimidade do nosso Estado democrático de direito, evidenciando a grande perda de objeto nessas situações, em especial os partidos pequenos e os de oposição.

Palavras-Chave: Democracia. Partidos Políticos. ADI.

\footnotetext{
Pós-graduanda em Ciência Política em UNICESUMAR, Bacharel em Direito pela Universidade Católica de Pernambuco (UNICAP) e Graduanda em Ciência Política com Ênfase em Relações Internacionais em Universidade Federal de Pernambuco (UFPE). E-mail: garaujotabosa@yahoo.com.br Orcid: https://orcid.org/00000003-1672-9245

2 Doutor em Ciência Política (UFPE), Mestre em Direito Público (UFPE), Professor no PPGD da Universidade Católica de Pernambuco (UNICAP). E-mail: jose.gomes@unicap.br Orcid: http://orcid.org/0000-0002-4003-856X
} 


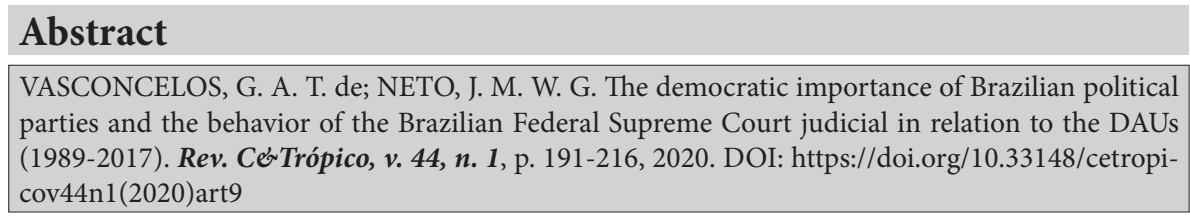

In order to understand our current society it is important to keep in mind a historical perspective of the evolutionary process that has taken place over time. From the origin of democracy in Ancient Greece to its modern form. The creation of the State as we know it today has enabled the implementation of representative governments, as in the case of Brazil. At the end of the Middle Ages and the beginning of the Modern Age, the diversity of social interests as well as the greater possibility of popular power, gave rise to the emergence of the first political parties. Until now they remain the bridge between citizens and government, are therefore entities of social representation in the political sphere and that seek to defend the interests of groups or social strata that have legitimized them by vote. Since they have immense relevance for contemporary democracies, it is natural that they are holders of various forms of political control where they act, of course, this is also happening in our country. Hence, armed with active legitimacy to propose Direct Actions of Unconstitutionality (DAUs), the national political parties also act in the Judiciary sphere while searching for the best defense of their interests. Thus, a quantitative research was developed using binary regression to better explain how the Federal Supreme Court responds to the DAUs filed by the parties and how this affects the legitimacy of our democratic state of law, evidencing the great losses of ground in these situations, in particular the small parties and the opposition ones.

\section{Keywords: Democracy. Political Parties. DAUs.}

\section{Resumen}

VASCONCELOS, G. A. T. de; NETO, J. M. W. G. La importancia democrático de los partidos políticos brasileños y el comportamiento de la corte suprema brasileña en el control de la constitucionalidad (1989-2017). Rev. CßTrópico, v. 44, n. 1, p. 191-216, 2020. DOI: https://doi.org/10.33148/ cetropicov44n1(2020)art9

Para comprender la sociedad actual, es importante tener en cuenta una comprensión histórica del proceso evolutivo que ha experimentado con el tiempo. Desde el origen de la democracia en la antigua Grecia hasta su forma moderna. La creación del Estado tal como lo conocemos hoy fue lo que permitió la implementación de gobiernos representativos, como en el caso de Brasil. Al final de la Edad Media y al comienzo de la Edad Moderna, la diversidad de intereses sociales, así como la mayor posibilidad de fuerza popular, llevaron a la aparición de los primeros partidos políticos. Hasta hoy siguen siendo un puente entre los ciudadanos y el gobierno, son, por lo tanto, entidades de representación social en el ámbito político y que buscan defender los intereses de los grupos o estratos sociales que los 
legitimaban con el voto. Dado que tienen una inmensa relevancia para las democracias contemporáneas, es natural que posean diferentes modalidades de control político donde actúan, evidentemente, esto también sucede en nuestro país. Por lo tanto, armados con una legitimidad activa para proponer Acciones Directas de Inconstitucionalidad, los partidos políticos nacionales también trabajan con el Poder Judicial en la búsqueda de la mejor defensa de sus intereses. A partir de eso, se desarrolló una investigación cuantitativa que utilizó la regresión binaria para explicar mejor cómo el Tribunal Supremo Federal responde a las ADI presentadas por las partes y cómo afecta directamente la legitimidad de nuestro estado de derecho democrático, lo que evidencia la gran pérdida de objetar en estas situaciones, especialmente partidos pequeños y opositores.

Palabras clave: Democracia. Partidos políticos. ADI.

Data de submissão: 18/04/2020

Data de aceite: 07/06/2020

\section{Introdução}

As Ações Diretas de Inconstitucionalidade (ADIs) representam um instrumento de controle constitucional inerentes ao nosso Estado Democrático de Direito, que vigoram no Brasil desde a Constituição de 1988. A partir de então, os legitimados, dentre os quais os partidos políticos, puderam exercer controle sobre o processo legislativo nacional.

A democracia por definição é o governo do povo e que, portanto, todos têm direitos a voz no governo. Hodiernamente, os partidos políticos atuam como representantes políticos dos cidadãos no exercício da gestão governamental. No entanto, com uma frequência exorbitante, é observável a perda de objeto nas ADIs propostas por partidos políticos junto ao Supremo Tribunal de Justiça (STF), que não analisa nem julga tais ações imparcialmente, o que configuraria um desrespeito ao princípio democrático (LIMA; GOMES NETO, 2016; CARVALHO, 2008).

A primeira parte deste trabalho retrata que o estágio de desenvolvimento democrático em que nos encontramos hoje é fruto de um longo processo. Enfoca no impostante debate acerca da melhor forma de analisar e pensar democracia na modernidade, seja a perspectiva minimalista da democracia defendida por Joseph Schumpeter ou a teoria da poliarquia elaborada por Robert Dahl. E, demostra a importância da participação popular para uma democracia efetiva, bem como a devida representação de interesses perante a estrutura governamental.

Na seção seguinte, é feita uma análise histórica de como surgiram os partidos políticos, entidades atualmente indispensáveis para a representação social no governo. Relata-se os dois principais momentos históricos que determinaram a criação dos primeiros partidos. A Revolução Nacional e a Revolução Industrial. Cada uma deu 
origem a duas clivagens sociais distintas que geraram seus respectivos partidos políticos. Há também menção ao debate acerca do Bi ou Pluripartidarismo e como cada um opera. O contexto brasileiro também é retratado, com especial ênfase ao momento do surgimento dos primeiros partidos ainda no período Regencial.

Por fim, a última parte é elaborada por meio de uma pesquisa quantitativa que fez uso de uma regressão logística binária para analisar a perda de objeto sofrida pelas Ações Diretas de Inconstitucionalidade propostas por partidos políticos no Supremo Tribunal Federal. O resultado dessa pesquisa mostra como alguns partidos são subjugados em detrimento de outros e como isso afeta o nosso sistema representativo e democrático. Desse modo, é possível observar a importância dada pelo legislador da Constituinte de 1988 aos partidos políticos como efetivos representantes das mais diversas camadas sociais e que por isso, devem dispor de diversas medidas para assegurar o devido regime democrático e a representação popular no governo. Valores esses tidos como indispensáveis para o Brasil.

Portanto, o controle de constitucionalidade tem íntima relação com a judicialização da política, uma vez que um agente político como representante do povo tem a necessidade de tomar medidas de gestão a fim de melhorar a vida da população, porém, nem sempre tais medidas estão de acordo com os Direitos Humanos e muito menos com normas e princípios previstos constitucionalmente e já que tem-se a “Carta Magna” como lei máxima no Brasil, não se admite tomar medidas que vão de encontro a suas disposições legais.

Este trabalho teve como objetivo analisar as ADIs propostas por partidos políticos perante a nossa Suprema Corte, nas quais foi possível observar seu recorrente comportamento autorrestrito. Tal questão se revelou ser de grande importância para a nossa sociedade, uma vez que prejudicaria todo o sistema democrático. A partir de um levantamento amostral aleatório das ADIs propostas pelos partidos políticos. Organizou-se uma matriz binária, baseada na ferramenta Logit, para analisar a proporção de ADIs que sofreram perda de objeto e se, o partido político que protocolou, bem como, sua posição de apoiador do governo ou não influenciariam no modo como seriam julgadas pelo STF.

\section{O debate democrático}

Ao longo do tempo, diante de todo o desenvolvimento sofrido pela democracia, vários debates ocorreram, no tocante às melhores formas de analisar esta forma de governo. Entre os principais teóricos da democracia, temos Joseph Schumpeter e Robert Dahl, cada um com uma perspectiva de análise e de melhor forma de exercer a referida forma de governo.

Segundo Schumpeter (1942), em uma democracia, o mais importante seria a escolha do representante e não a vontade do povo. Ou seja, as elites políticas, através do processo eleitoral, adquirem o poder de decidir pelos eleitores. Nesse sentido, com um grande destaque para o papel das lideranças, o autor acredita que é democrático o 
governo que tiver eleições, visto que a democracia seria um mero procedimento e não a soberania popular. Coloca aquela, portanto, como um meio e não um fim, sendo, um espaço de luta pelas lideranças pelo voto livre.

Acredita que o povo não é racional e por isso possuem a mera função de eleger políticos devidamente treinados para exercer a função pública. Além disso, ainda estabelece algumas condições para o êxito do método democrático, tais como: uma elite política bem capacitada, não estender a democracia para outras partes da sociedade, uma burocracia que funcione bem e o autocontrole democrático (uma cultura de aceitação das decisões que são tomadas pelos governantes). Esse cenário caracteriza uma concepção minimalista da democracia, tendo-a como um mero e pouco inclusivo procedimento.

Por outro lado, Robert Dahl (1997), analisou a democracia através de um método de maximização, no qual estabelece um conjunto de metas e a melhor forma de realizá-las. Utiliza também um método descritivo para melhor compreender e elucidar as estruturas democráticas do mundo real. O autor criou uma democracia considerada ideal, chamada democracia poliárquica que se constituiria de oito normas. Estas se tornam os critérios para analisar as democracias reais, ou seja, são métricas para classificar formas de governo e estabelecer o que seria necessário para que tais normas existam em maior ou menor grau.

As normas são necessárias em momentos eleitorais (período de votação, bem como antes e depois) e em períodos entre eleições. E possuem como principal objetivo maximizar a soberania popular e a igualdade política. As normas são: 1) Todos têm o direito de votar; 2) Peso igual para os votos; 3) A maioria vence; 4) Qualquer pessoa não satisfeita com as alternativas propostas poderá inserir a que se identificasse (propostas alternativas); 5) Todos os indivíduos possuam informações idênticas sobre as alternativas; 6) Propostas e líderes majoritários substituem os minoritários; 7) As ordens dos servidores públicos eleitos devem ser executadas; e 8) Todas as decisões devem ser subordinadas às 7 normas anteriores.

Dessa forma, tendo tais normas como critérios, o mundo se dividiria (em ordem decrescente) em: poliarquias (igualitárias ou não) e hierarquias (oligarquias ou ditaduras). A democracia em si seria um ideal a ser atingido e em realidade, temos apenas uma aproximação dela eu seria a poliarquia. Com isso, existiria mais poliarquia onde mais se aceitasse que as normas referidas são importantes, ou seja, a existência de poliarquias está muito relacionada à ideia de cultura política do local analisado. Neste, a sociedade democrática que existir treina em preceitos democráticos na sua rotina, através da participação, para sempre manter tais preceitos claros ao povo.

A partir de tal debate, observa-se que as diferentes perspectivas acerca da democracia nos levam a crer que a forma mais participativa e, a princípio, mais justa para a sociedade seria a teoria de Robert Dahl. É importante ter em mente que, apesar de não termos atingido uma democracia de fato, na visão do autor, não seria interessante deixar de persistir nesse intuito e ceder o poder as elites políticas e nos contentarmos om uma forma minimalista e procedimental da democracia. 


\section{O contexto de surgimento dos partidos políticos e o processo de desenvolvimento}

\subsection{Origem}

Os partidos políticos surgiram na Inglaterra no século XVIII, em um contexto de restituição do governo monárquico após a série de conflitos que culminou com a decapitação de Carlos I. Entre este e o seu sucessor, Carlos II, o país foi governado por Oliver Cromwell, como Lorde Protetor até a sua morte em 1658. Momento este em que foi sucedido por seu filho Richard que, no entanto, não havia herdado a desenvoltura política do pai e foi compelido a deixar o cargo. Após muita deliberação por parte do Parlamento, Carlos II assumiu sua posição como monarca, mas não da mesma maneira que seu pai havia feito, no tocante a importância dada ao Congresso Nacional.

Segundo Williamson (2013), o reinado de Carlos II o relevou como um soberano pragmático e, portanto, devido às crescentes demandas sociais, permitiu que o Parlamento começasse a desenvolver o sistema partidário, tendo os Whigs (Partido Liberal) e os Tories (Partido Conservador) emergido pela primeira vez.

O Guia Oficial do Palácio de Westminster, produzido pelas Houses of Parliament, relata que, a partir do século XVIII, período em que houve um considerável aumento de demandas públicas para a participação na política, os Comuns começaram a exercer grande controle sobre as matérias financeiras, fato que, eventualmente, tornou a House of Commons dominante, bem como que a monarquia também passou a desempenhar um papel menos significante na gestão da nação. Naquela época, a política nacional de partidos evoluiu gradativamente e o atual sistema de dois ou três partidos principais se desenvolveu no século XIX.

Este estudo ressalta ainda que, no século XX, o relacionamento entre as casas representativas mudou sua configuração. O Ato Parlamentar de 1911 removeu a prerrogativa do veto legislativo para receitas e despesas da House of Lords. Diversificou-se também o corpo de membros da referida Casa. Antes apenas Pares do Reino, leia-se, nobres, de maneira hereditária poderiam se tornar membros, após a reforma, estendeu-se a possibilidade de nela ingressar também pessoas de notável saber e reputação. Como resultado, atualmente se tem uma Câmara mais diversa e ativa no processo legislativo. A Câmara dos Comuns, por sua vez, também se tornou mais representativa da realidade social e, uma vez que se tornou preponderante no Legislativo, passou também a dar um ar de efetiva democracia à Inglaterra, posto que era o local de atuação dos partidos políticos e do sistema partidário em si.

Ainda sobre a origem dos partidos políticos, vale menção o doutrinador jurídico José Jairo Gomes (2013), em sua obra referente a Direito Eleitoral, ele afirma que o processo de formação dos partidos se deu através da atuação de deputados no Parlamento. Aponta também que já no século XVII começaram a ocorrer 
movimentos de contestação aos excessos do poder monárquico-absolutista, além de ressaltar que o início do desenvolvimento de ideias liberais, que por sua vez, enfatizavam a liberdade individual frente ao Estado, também foram determinantes para o processo.

A Revolução Industrial se mostrou de extrema importância para catalisar a formalização dos partidos, já que seus movimentos socialistas ajudaram a firmar a distinção ideológica entre Conservadores (Tories) e Liberais (Whigs). O contexto desse período teve início em 1832 com a lenta e progressiva ascensão da burguesia industrial, bem como a da massa trabalhadora, ou seja, os operários, que se sindicalizaram e formaram as trade-unions. Em decorrência disso, o nível das reivindicações culminou com o Partido Trabalhista (Labour Party) e sua busca pela representação dessa parcela da população no Parlamento. Uma nota histórica relevante é que o Partido Liberal entrou em declínio na atualidade, sendo, portanto, o cenário político contemporâneo na Inglaterra dominado, em sua maioria, pela disputa entre os partidos Conservador e Trabalhista (GOMES, 2013).

Para o nosso sistema de democracia moderna, os partidos políticos se tornaram peças essenciais para o seu funcionamento. Assim, sua importância é tamanha que, no Brasil, detêm o monopólio do sistema eleitoral e chegam a definir o perfil assumido pelo governo. Desse modo, não há representação popular nem tampouco exercício de poder estatal sem a intermediação partidária. Atuam, nesse sentido, como mecanismo de comunicação (entre a população e o governo) e de participação do processo de decisão, ou ainda como instrumento destinado ao recrutamento dos governantes e à socialização política. Tornaram-se indispensáveis à normalidade democrática e a possível ausência deles poderá induzir uma resposta violenta de setores da sociedade que se sentirem prejudicados e excluídos no âmbito da representação no nosso sistema democrático (GOMES, 2013).

\subsection{Movimentos Históricos Determinantes}

Entretanto, de acordo com Jalali (2017), em seu livro Partidos e sistemas partidários, a motivação que levou a origem desses agrupamentos se deu através de movimentos históricos no espaço social que culminaram em fraturas sociais que perduraram ao ponto de gerarem dimensões de conflito que dividiram a sociedade e consequentemente suas prioridades políticas. O autor dá destaque para dois acontecimentos, são eles: a revolução nacional e a revolução industrial, que deram origem a duas clivagens (termo referente a divisão ou separação) sociais cada.

A revolução nacional diz respeito ao complexo processo de formação dos atuais Estados da Europa Ocidental, após a Paz de Vestfália. No decorrer disso, houve a construção de vários Estados multinacionais, uma vez que abarcavam diversas várias nações nos limites de suas fronteiras, como no caso da Espanha ou do Reino Unido. Nessas localidades, existem imensos debates políticos suscitando referendos ou outras tentativas de independência de nações que integram os atuais Estados. 
Os conflitos que deram origem a esses Estados tiveram como resultado a subordinação do grupo derrotado ao grupo vencedor, fato que gerou a clivagem centro-periferia. Isso, contudo, não diz respeito a uma dimensão geográfica e sim a uma divisão entre vencedores (centro) e derrotados (periferia). A "cultura central" da construção nacional versus a crescente resistência das populações dominadas étnica, linguística ou religiosamente. Trata-se, portanto, de uma clivagem referente à construção territorial e cultural dos Estados modernos (JALALI, 2017).

Outra divisão social originada da revolução nacional se prende ao próprio desenvolvimento das estruturas do Estado moderno. A provisão direta ou indireta de uma série de bens, que hoje atribuímos ao governo, tais como educação, proteção social, saúde e a definição de regras (Direito Canônico), outrora foram prerrogativa da Igreja (Católica, Luterana ou Calvinista). Emerge assim o conflito entre as aspirações mobilizadoras do Estado-nação e as exigências corporativas das Igrejas. A clivagem Estado-Igreja abarca a divisão entre aqueles que defendem a manutenção do papel da Igreja e aqueles que defendem a redução desse papel e a sua substituição pelo Estado (JALALI, 2017).

A Revolução Industrial, por sua vez, foi um momento histórico que se desenvolveu sobretudo nos séculos XVIII e XIX e seus efeitos são amplamente conhecidos e sentidos até a atualidade. Já que poucas são as esferas da vida que não foram afetadas por ela. Esse novo meio de produção gerou duas clivagens sociais. A primeira foi a clivagem rural-urbana que abarcava os interesses divergentes dos grupos agrícolas e industriais. Ou seja, derivava de questões econômicas e, portanto, sediava as disputas entre os setores fabris, que tinham interesse em promover o comércio livre, nacional e internacionalmente, em contraste com os interesses agrícolas que defendiam uma maior proteção dos mercados.

Contudo, tal disputa tem um caráter mais profundo, pois, em seu cerne, os interesses rurais visavam defender suas terras, bem como sua posição histórica de elite nacional, enquanto que os interesses urbanos/industriais reivindicavam acesso a essa elite, pelo seu mérito e capacidade de empreendimento (JALALI, 2017).

Tal situação é, por exemplo, bem visível no contexto britânico. Posto que tal país, com sua forte tradição monárquica, garantia aos nobres e pares do reino um status hereditário e vitalício no comando do país e não incentivava a ascensão social. Mas o novo contexto econômico muitas vezes permitia a não-aristocratas uma imensa fortuna, por vezes maiores do que a de muitos fidalgos, fato que gerava muito inconformismo social na época e a crescente busca por mais representatividade de cidadão não possuidores de título nobiliárquico.

Michael St John Parker (2013), em seu livro "Life in Victorian Britain", relata que, apesar do crescimento das cidades, certos aspectos da Inglaterra vitoriana permaneceram rurais. A aristocracia latifundiária vivia confortavelmente em suas propriedades e fazendas, mas aqueles que faziam dinheiro a partir da indústria e do comercio eram, no geral, rápidos em investir em terras. A agricultura em si passou por um difícil período nos anos de 1840. Com isso, a massa trabalhadora passou a migrar para as cidades e a buscar emprego nas indústrias. 
O cenário político da época, assim, poderia ser visto no sentido de que a nobreza foi paulatinamente tendo seu poder de influência reduzido, ricas e bem-sucedidas classes médias tomaram o controle do sistema político e as classes trabalhadoras começaram sua própria ascensão ao poder devidamente organizado. Ideias políticas passaram a ser levadas adiante com grande entusiasmo por todos os níveis da sociedade (PARKER, 2013).

Todavia, atualmente esta clivagem tem pouca visibilidade, pois houve um grande declínio da população agrícola e os partidos tiveram que posicionar-se. Em contrapartida, o confronto entre patrões e trabalhadores destaca-se como sendo o mais importante. E, de acordo com Jalali (2017), encontra-se na origem da divisão entre esquerda e direita e, portanto, com os partidos de esquerda com tendências a defender os valores e interesses da classe trabalhadora e uma maior intervenção do Estado na economia. Isso é visto, pela literatura científica, como o principal conflito político da Europa Ocidental, e por consequência, dos principais países do continente americano também, tendo em vista a forte influência cultural que ainda sofremos por parte de nosso continente colonizador (JALALI, 2017).

Ressalte-se que é através desta clivagem patrões-trabalhadores que melhor explica o voto nas democracias ocidentais. Daí, tal contexto se solidificou principalmente após a Revolução Russa de 1917 e está presente até hoje nos mais diversos países ao redor do mundo, inclusive no Brasil (JALALI, 2017).

No caso do Brasil, para a maioria dos pesquisadores, o primeiro partido político surgiu em 1831 e denominava-se liberal. Em seguida, no ano de 1838, foi criado o Partido Conservador, sendo ambos frutos de uma intensa atividade político-partidária. Nos primeiros anos do Império, não existiam propriamente partidos políticos como temos hoje, e sim, apenas grupos de opinião. Estes, contudo, não eram bem organizados nem suficientemente duradouros para serem caracterizados como partidos. Além disso, o período conturbado do primeiro reinado não favoreceu a formação de grupos coesos e o fato de D. Pedro I ter governado algum tempo com o parlamento fechado constituiu-se numa dificuldade adicional (GOMES, 2013).

Já na fase do Segundo Reinado (incluindo o período regencial), o cenário político brasileiro foi dominado pelos partidos Liberal e Conservador, época em que vigorou uma certa estabilidade no quadro partidário nacional. Como tais partidos não diferiam muito substancialmente, em 1870 é criado o Partido Republicano, que por sua vez, viria a desempenhar um papel decisivo na queda do Império e na formatação da República, sob inspiração dos EUA (GOMES, 2013).

Desde a instalação da República até os dias atuais, a história dos partidos políticos brasileiros tem sido tumultuada e repleta de acidentes. No período compreendido entre a nossa independência e a contemporaneidade, houve seis diferentes sistemas partidários no Brasil. E são resultantes de diversas mudanças sofridas nas estruturas do Estado geradas por revoluções e golpes políticos, que geraram extinções e formações de novas organizações. Portanto, se comparado a outros países, especialmente os EUA e as nações da Europa ocidental, onde os sistemas partidários são estáveis dentro do possível, no Brasil, há uma trajetória de marcante instabilidade (GOMES, 2013). 
Com isso, é importante entender a relação entre o modelo de clivagens, detalhado anteriormente, e a formação e consolidação dos sistemas partidários. Estes dizem respeito à forma de interação que existe entre os diversos partidos e como eles se relacionam no contexto nacional em sua incessante busca pelo poder. Em termos gerais, portanto, a estrutura de um sistema partidário deriva da natureza das clivagens dentro de suas respectivas sociedades (JALALI, 2017).

Nesse sentido, os diferentes partidos transferem os conflitos resultantes das clivagens sociais para a arena política e, da configuração destes conflitos emergem as interações entre os partidos, ou os sistemas partidários. Em geral, os países têm diferentes dinâmicas, visto que os processos evolutivos e revolucionários variaram de acordo com a realidade histórica de cada um. Ou seja, os reflexos das revoluções nacional e industrial trouxeram diversas clivagens que, posteriormente, geraram um sistema partidário próprio a determinado país (JALALI, 2017).

Por exemplo, no caso britânico, por ter sido pioneiro nesse quesito, o timing e a natureza das revoluções levaram à predominância da clivagem patrões-trabalhadores, o que ajuda a explicar a estruturação do sistema partidário numa dimensão de competição principal entre os partidos Trabalhista e Conservador. Ainda que existissem outros interesses, o momento foi mais propício para que essa clivagem se tornasse o cerne do debate político naquele país (clivagem dominante), contribuindo assim para a consolidação do sistema partidário em torno destes dois partidos (JALALI, 2017).

Daí, as fraturas sociais tornam-se parte da "paisagem" social e política do país e, geram as alternativas partidárias que, em democracias consolidadas (especialmente na Europa Ocidental), são mais antigas do que a maioria dos eleitorados nacionais. Assim, para muitos cidadãos, as principais opções eleitorais que lhe são apresentadas eleitoralmente, existem até mesmo antes de nascerem e lhe foram passados por seus ancestrais, numa relação que perdura gerações. Por isso, pode-se resumir que a consolidação dos sistemas partidários se dá pela formação de clivagens sociais, que geram partidos e estruturam os sistemas partidários.

\subsection{Sistemas Bi ou Pluripartidários}

Ao redor do mundo, os partidos políticos só passaram a ser regulamentados por normas constitucionais a partir do final da Segunda Guerra Mundial. Destarte, os regimes democráticos repartem-se em bi ou pluripartidaristas e, quando em alguns países, momentânea ou duradouramente, os partidos são suprimidos a um ou nenhum na esfera governamental, não seria possível classificá-los como democracias. Visto que o princípio base do regime democrático é a disputa pelo poder por diversos segmentos sociais e a devida representação de todos, dentro do possível. Ou seja, a alternância e poder e constante incerteza acerca do próximo governante, fazem parte de um Estado democrático de fato (PRZERWORSKI,1984).

No tocante a ausência de partidos, ela pode ocorrer pela impraticabilidade eleitoral, em governos de duração indefinida. Já o partido único, é comum em 
regimes ditatoriais e autoritários como no caso da Itália fascista. Ressalte-se os partidos de ideologias marxistas, que alegam ser transitórios e atuarem apenas como ponte entre o socialismo e o comunismo, conforme defendia Mao Tse Tung ao afirmar que o pluripartidarismo seria uma consequência do Estado burguês, onde cada partido defenderia sua classe. De certo modo, tal teoria faz um certo sentido, como já foi mostrado os processos históricos que originaram os partidos políticos (MENDONÇA, 1981).

O bipartidarismo, por sua vez, é defendido por aqueles que acreditam que o dualismo é a ordem natural da política. E que, portanto, as decisões finais sempre se dão entre duas possibilidades, ainda que hajam vários partidos, no Congresso, as votações são entre duas hipóteses. Daí, a pluralidade aparente se transforma em dualidade real. No entanto, o bipartidarismo, a rigor, exige que os dois partidos aceitem esta forma de representação popular, sendo ambos, permanentemente, sucessores potenciais um do outro. Essa efetiva possibilidade de alternância tem que ser assegurada caso contrário, o regime se torna ilusório (MENDONÇA, 1981).

Inglaterra e EUA são exemplos clássicos de democracias bipartidárias. $\mathrm{Na}$ Inglaterra, os partidos é que são fortes e não os candidatos ou líderes, propriamente, e assim, são raras as mudanças violentas de votação entre dois partidos, porque a população tende a seguir a ideologia do partido e acompanhar seus programas e propostas. Porém, nos EUA, a eleição do governante se dá mais pelo compromisso que o candidato defende do que na opinião difundida ou dogma seguido pelo partido ao qual é vinculado (MENDONÇA, 1981).

No Brasil, já houve tanto a experiência do Bi quanto do pluripartidarismo. A primeira se deu ainda no período do império e perdurou até o surgimento do Partido Republicano que, após vinte anos no poder, pôs fim ao nosso regime monárquico e instaurou a república, mas não por meio do voto, e sim através de insatisfações sociais, militares e religiosas. Após esse evento, a nossa estrutura partidária fragmentou-se e foi pulverizada em um sistema estadual que era pouco autêntico em sua representação, por cerca de 40 anos. A cobrança por mais legitimidade representativa foi, inclusive, um dos postulados da Revolução de 30 (MENDONÇA, 1981).

O bipartidarismo também esteve presente no período do governo militar no Brasil. Contudo, com o processo de redemocratização e a promulgação da atual Constituição, o país ingressou em sistema pluripartidarista. Esse sistema, apesar de ter como objetivo garantir a maior representação possível da sociedade, muitas vezes inspira a criação de novos partidos apenas para fortalecer os interesses das camadas governantes.

No entanto, é importante mencionar o âmbito legal dos partidos. Juridicamente, são tidos como entidades formadas pela livre associação de pessoas, cujas finalidades são assegurar, no interesse do regime democrático, a autenticidade do sistema representativo, e defender direitos humanos fundamentais, tal como os direitos políticos do cidadão (GOMES, 2013). Destarte, conforme mencionado anteriormente, tais instituições, no decorrer na história brasileira não abarcam as aspirações e necessidades de 
todos, ou ao menos grande parte, da nação, por isso as constantes crises de representatividade sofridas pelo cenário político.

Em tese, cada filiado encontra-se ligado a outro por princípios filosóficos, sociais, doutrinários, que se presume respeitar, culminando, assim, na chamada lealdade partidária. Porém, ainda que nosso arranjo eleitoral conte com um balizamento legal bom, não é possível dizer que o sistema partidário nacional é estável. A estabilidade desse sistema se dá por meio da reprodução das estruturas sociais geradas pelas clivagens, no seio de uma própria comunidade ou até mesmo de uma família. Nesse sentido, a estabilidade decorre da continuidade das estruturas sociais geradas pelas várias clivagens (JALALI, 2017). Fato esse não observado no Brasil, cuja sociedade se encontra em constante mutação, especialmente a partir dos anos 2000, mas sem perder o almejo ao governo e ao poder.

Em outras partes do mundo, em especial o "Velho Mundo", tomando como exemplo a clivagem patrões-trabalhadores, a estabilidade era gerada pela existência continuada de uma ampla classe trabalhadora, após a Revolução Industrial. Esse mesmo padrão existia nas outras clivagens como a Estado-Igreja ou a centro-periferia. Daí, pode-se extrair uma explicação socioestrutural, na medida em que se prende com a manutenção das estruturas sociais que apoiavam os diferentes partidos. Ou seja, uma sociedade estável implica em um sistema político-partidário estável porque, enquanto não houver conformação nesse sentido, será inviável uma concorrência partidária previsível (JALALI 2017).

Ao mesmo tempo, também se pode atribuir a estabilidade de um sistema partidário ao importante papel da socialização das identidades geradas pelas clivagens, em que as novas gerações absorveriam os valores identitários e políticos das gerações precedentes, processo que ocorre principalmente no meio familiar. Isso ajudava a desenvolver uma consciência política da identidade religiosa ou regional por parte do indivíduo. A noção de uma pessoa como fruto do seu entorno e a reprodução dos valores apreendidos ao longo da vida, bem como a sedimentação e reprodução desses valores na esfera político-social (JALALI, 2017).

As identidades políticas também podem ser derivadas de uma dimensão organizacional. Havia uma densa rede de organizações que contribuíam para a difusão, organização e mobilização dos diferentes grupos sociais, tais como: sindicatos, Igreja ou ainda partidos políticos. Estes últimos, entram nos elencados, no tocante a uma espécie do gênero partidos políticos. E são aqueles que visavam a organizar e representar os interesses de sua camada social, originada a partir da estrutura de clivagens. Possuíam uma elevada estabilidade ideológica e eram fiéis aos interesses do seu grupo social de apoio. Contavam com um forte enraizamento na camada social que visavam defender e eram chamados de "partidos de integração de massas" ou também de "partidos de massas" (JALALI, 2017).

Diante do exposto e de volta ao contexto brasileiro, nosso país prevê, em sua Constituição Federal de 1988, que "É livre a criação, fusão, incorporação e extinção de partidos políticos, resguardados a soberania nacional, o regime democrático, o 
pluripartidarismo, os direitos fundamentais da pessoa humana”. Estabelece ainda alguns preceitos a serem seguidos, tais como: caráter nacional, proibição de recebimento de recursos financeiros de entidade ou governo estrangeiros ou de subordinação a estes, prestação de contas à Justiça Eleitoral e funcionamento parlamentar de acordo com a lei. Além disso, assegura aos partidos políticos autonomia para definir sua estrutura interna, organização e funcionamento e para adotar os critérios de escolha e o regime de suas coligações eleitorais, sem obrigatoriedade de vinculação entre as candidaturas em âmbito nacional, estadual, distrital ou municipal, devendo seus estatutos estabelecer normas de disciplina e fidelidade partidária.

O regime democrático no Brasil sempre se deu de forma representativa, até porque seria altamente inviável em sua forma direta nos moldes da Grécia Antiga bastando para isso levar em consideração o tamanho da nossa população em comparação com a de Atenas Clássica. Por isso, fazemos uso de partidos políticos dotados de diversas garantias e preceitos que visam ao melhor interesse da população nacional quando esta estiver sendo representada no Congresso.

Uma garantia fundamental nesse sentido é que os partidos estão abarcados entre os legitimados no país para propor Ações Declaratórias de Inconstitucionalidade (ADIs). Isso é uma prova da importância democrática dessas entidades para o cenário político nacional pois, além da arena que lhes cabe no Poder Legislativo para debater questões, também podem fazer uso da esfera do Poder Judiciário se acreditarem ser necessário e no melhor interesse da nação combater uma possível ofensa à Carta Magna brasileira.

\section{As ADIs propostas pelos partidos políticos brasileiros e o com- portamento do STF}

\subsection{Objetivo das ADIs}

A legislação brasileira estabelece alguns meios de controle de constitucionalidade, dentre eles a ADI (Ação declaratória de inconstitucionalidade ou Ação direta de inconstitucionalidade). Luís Roberto Barroso, em seu manual de Direito Constitucional Contemporâneo, define este instrumento processual como controle de constitucionalidade de ato normativo em tese, abstrato, marcado pela generalidade, impessoalidade e abstração. Busca-se, com isso, expurgar do sistema uma lei ou ato normativo viciado (formal ou materialmente) através da invalidação deste ato normativo ou desta lei, tendo por objeto a própria questão da inconstitucionalidade (BARROSO, 2013).

A Constituição Federal de 1988 e o Regulamento Interno do Supremo Tribunal Federal estabelecem que o processo e o julgamento das ADIs deverão se dar perante o STF. A ação deverá ser proposta por um dos legitimados, dentre os quais se encontram os partidos políticos.

No Brasil, diferentemente de alguns lugares do mundo, todo partido político que possua representação no Congresso Nacional, ainda que seja apenas um 
representante, tem legitimidade ativa universal para propor ADIs. Já em outros países, é, muitas vezes, exigido um número mínimo de representantes em suas respectivas Casas Legislativas para que o partido tenha essa prerrogativa. Contudo, nem o diretório nacional nem a executiva regional têm legitimidade para propor a ação, pois não podem agir nacionalmente em nome do partido político e este deve representar no nosso Parlamento, os interesses nacionais que defende (MORAES, 2008).

Segundo o STF, a aferição da legitimidade ativa do partido deve ser feita no momento da propositura da ação e que a perda posterior da representação no Congresso não o desqualifica como legitimado para a ação. Ou seja, se o partido perder sua representação durante a tramitação da ação, esta não será prejudicada (MORAES, 2008).

Com isso, é possível observar a importância dada pelo Constituinte de 1988 aos partidos políticos como efetivos representantes das mais diversas camadas sociais e que, por isso, devem dispor de diversas medidas para assegurar o devido regime democrático e a representação popular no governo. Valores esses tidos como indispensáveis para o Brasil.

O controle de constitucionalidade caracteriza-se, em princípio, como um mecanismo de correção presente em determinado ordenamento jurídico, consistindo em um sistema de verificação da conformidade de um ato em relação à Constituição. As normas constitucionais possuem um nível máximo de eficácia, obrigando os atos inferiores a guardar uma relação de compatibilidade vertical para com elas. Se não for compatível, o ato será inválido, daí a inconstitucionalidade ser a quebra da relação de compatibilidade no aspecto formal e material. Para que um sistema jurídico funcione, pressupõe-se sua ordem e unidade, devendo as partes agir de maneira harmoniosa. $\mathrm{O}$ mecanismo de controle de constitucionalidade procura restabelecer a unidade ameaçada, considerando a supremacia e a rigidez das disposições constitucionais.

Nesse sentido, o controle de constitucionalidade tem íntima relação com a judicialização da política, uma vez que um agente político como representante do povo tem a necessidade de tomar medidas de gestão a fim de melhorar a vida da população, porém, nem sempre tais medidas estão de acordo com os Direitos Humanos e muito menos com normas e princípios previstos constitucionalmente e já que tem-se a "Carta Magna” como lei máxima no Brasil, não se admite tomar medidas que vão de encontro a suas disposições legais. Assim, várias ADIs são propostas para conter tais medidas e com isso se gera um controle judicial de matérias que originalmente seria de atribuição do Poder Executivo. Daí dizer que quando o Poder Judiciário realiza essa fiscalização em detrimento do Executivo, cria-se um processo de judicialização da política, fato esse bastante recorrente em nosso país (CARVALHO, 2007).

\subsection{Processo de Tomada de Decisão}

Contudo, essa Judicialização da política tende a gerar por um lado um ativismo judicial e por outro uma autorrestrição. $\mathrm{O}$ primeiro diz respeito às atitudes tomadas pelo Poder Judiciário que, a rigor, vão além de suas atribuições originárias 
e que, portanto, ocupariam espaço destinado a atuação do Executivo que deixa de fazê-lo, muitas vezes, pelas mais variadas razões. Já a segunda refere-se aos momentos em que o Judiciário deixa de atuar em matéria que lhe foi originalmente delegada. $O$ interessante é que ambas as situações são verificadas no cenário nacional, tendo em vista a elevada tendência atual das cortes de somente julgar casos que lhe convêm e deixar de lado os que demandem posicionamentos impopulares, demonstrando a presença comportamentos estratégicos (SEGAL; COVER, 1989).

Este último dá-se quando juízes levam demasiadamente em conta a opinião pública que suas decisões teriam antes de tomá-las, ou seja, preveem as possíveis reações da opinião pública e da política antes de proferir seu voto. Isso ajuda a compreender uma série de fatores relacionados a judicialização, como por exemplo, quais as forças políticas interessadas, se tem ou não pressão interna ou externa, etc. Tal fato, muitas vezes, leva os magistrados a se omitirem de certos julgamentos que lhe foram demandados por meio de represálias tanto internas quando externas ao órgão judicial, gerando assim a perspectiva da autorestrição do Poder Judiciário. Ou seja, "Esta se encarrega da prescrição sobre os critérios a serem observados nas decisões e posturas do judiciário na sua atuação, (...), ao levar em consideração o exercício de uma atividade política. ” (LIMA, 2014, p. 24).

Tal autorrestrição pode ter como pior consequência a perda do objeto litigado, e isso se dá quando a corte se omite a ponto de tornar a demanda impossível devido ao seu perecimento. Assim, prejuízos incalculáveis são gerados com esta atitude do judiciário de se esquivar de demandas muitas vezes impopulares e que culminam em pretensões não mais atingíveis.

Articulações políticas podem ser tidas como uma das razões pelas quais o STF se omite ao receber ADIs formuladas por partidos políticos pois, estes, muitas vezes, propõem tais ações objetivando atingir partidos rivais e se promoverem diante dos eleitores. Contudo, existem situações em que tais ações são legítimas e a Suprema Corte deixa de julgá-la como em prestação de favor a algum aliado pertencente ao Congresso ou com alto cargo no Poder Executivo e isso gera uma "politização do órgão jurisdicional" e consequentemente uma grande insegurança quanto a credibilidade do STF.

Desse modo, um exame minucioso dessas ADIs propostas pelos partidos políticos nacionais ajudará imensamente a compreender o real funcionamento do "guardião de nossa constituição" que nem sempre age baseado na devida previsão legal, mas sim em proveito próprio e de seus aliados. Podem, inclusive, deixar de lado demandas tidas como essenciais para nossa sociedade.

Com isso, as atitudes autorrestritivas da nossa Suprema Corte, baseadas em esperar que a perda do objeto demandado se concretize ao ser posteriormente declarado como inconstitucional o fundamento em que se baseou a pretensão, gerando assim, a alegação necessária para declarar o objeto como não mais relevante no momento de seu julgamento e não quando foi proposto. Assim, diversas ações têm seus julgamentos postergados com a finalidade de que com o tempo, a matéria 
requerida seja tida como inconstitucional e isso baseie a fundamentação do STF quando for proferir a sentença e o exima de ter de tomar decisões impopulares ou que afete negativamente seus arranjos políticos.

Analisar as ADIs propostas por partidos políticos perante a nossa Suprema Corte se revelou ser de grande importância para a nossa sociedade, uma vez que prejudicaria todo o nosso sistema democrático pelo fato de o Poder Judiciário atuar parcialmente quando provocado pelo Poder Legislativo.

Nesse sentido, o controle de constitucionalidade também fica comprometido, pois o órgão que deveria realizá-lo não o faz por colocar em prática modelos de atuação visíveis aos magistrados e a outros agentes políticos que seriam demonstrados pelas seguintes hipóteses: A hipótese legalista concebe a decisão judicial como sendo a atividade de verificar como e quando será aplicada a norma jurídica diante de determinada situação fática posta a partir do conflito de interesses que foi submetida ao Poder Judiciário. Na hipótese atitudinal, os Juízes agiriam diretamente em favor da realização das políticas públicas que melhor refletem suas preferências ideológicas e políticas originais. Já na hipótese estratégica, constrangimentos externos à Corte podem gerar incentivos institucionais a que os juízes, no caso, os Ministros Presidentes, comportem-se de maneira estratégica, sendo intuitivo dirigir o olhar aos demais atores e instituições que interagem com o Poder Judiciário (GOMES, no prelo).

Desse modo, é possível observar as diferentes formas de julgar existentes. $\mathrm{O}$ que interessa a este estudo é como elas podem interferir nas ADIs propostas por partidos políticos a depender do partido e se na época em que o referido instrumento constitucional foi proposto, ele se encontrava apoiando a situação governamental ou a sua oposição, sem prejuízo a inclusão se outras variáveis caso venham a ser necessárias. Assim, busca-se testar as variáveis de modo a concluir se nossa suprema corte age parcialmente ao julgar tais remédios constitucionais parcialmente e descobrir em qual hipótese comportamental seus entendimentos predominam.

Em um âmbito global, nosso país não está isolado nesse sentido, uma vez que, ao longo da história, a implementação dos Tribunais Constitucionais em diversos países, como mecanismo de controle dos demais poderes, implicou em mudanças na forma de pôr em prática as políticas públicas pleiteadas pelos governos. Visto que estes além de negociarem com as casas parlamentares, precisam também ter atenção aos preceitos constitucionais, o que geraria uma assimetria entre os poderes. A expansão do poder judicial torna-se mais visível a partir da verificação de um quadro de condições que tende a se repetir nas democracias em que este fenômeno é observado. No Brasil, isso é observável no diagnóstico dado ao aumento das ações judiciais.

Ao redor do mundo, acredita-se que a expansão do poder judicial se deu por diversos motivos, entre eles: a queda do comunismo, os EUA terem se tornado modelo para as novas democracias (que passam a utilizar a "Judicial Review" em seus ordenamentos), como também o fim da Segunda Guerra Mundial e a 
consequente valorização dos Direitos Humanos após os traumas decorridos dos conflitos. Nesse sentido, as condições políticas para o surgimento da judicialização têm como pilares a democracia, a separação dos poderes, a garantia e efetivação dos direitos políticos, o uso dos tribunais pelos grupos de interesse (pois trata-se de um processo que emana dos interesses econômicos e sociais centrais, cujos grupos passam a utilizar o veto dos tribunais na realização dos seus objetivos, fazendo uso de ADIs, por exemplo), o uso dos tribunais pela oposição (partidos políticos muitas vezes não conseguem barrar determinadas alterações no parlamento e fazem uso dos tribunais para impedir ou inviabilizar tais alterações contrárias ao que acreditam) e a inefetividade das instituições majoritárias (tribunais ficam obrigados a resolverem demandas sociais que deveriam ser tratados no âmbito político) (CARVALHO, 2004).

No Brasil, o controle de constitucionalidade exercido junto ao STF poderá ser exercido somente pelos agentes elencados no próprio texto legal. Dentre os possíveis instrumentos a serem usados para este fim, o mais relevante é a propositura de ADIs referentes aos cenários legais e políticos do país. Contudo, dependendo do contexto em que são propostas e do jogo político que as envolve, tais ações, muitas vezes deixam de ser julgadas (demostrando o comportamento autorrestritivo de nossa Suprema Corte) propositalmente a fim de gerar perda de objeto. Ou seja, o tribunal, não querendo se comprometer ao julgar determinada temática ou deixa de fazê-lo visando interesses políticos, posterga o máximo possível o julgamento agindo assim, estrategicamente. Comprometendo com isso, o sistema democrático ao fazer uso de argumentos formais e procedimentais para evitar o processo e deixar a tarefa de decidir tal situação, no caso concreto, para os órgãos legitimados pelo sufrágio (LIMA, GOMES; BARBOSA, 2016).

Para um entendimento melhor acerca da autorrestrição, é indispensável se ter uma visão acerca do papel que o Judiciário desempenha em determinada sociedade democrática. Assim como mostrar a importância de inclusão do deste Poder em um ambiente político e as dificuldades que este enfrenta para exercer essa tarefa. Visto que, dependem da aceitação popular das decisões tomadas pelo Tribunal. Essa prerrogativa, dá poderes de veto de uma minoria parlamentar contra a maioria, em decisões que acreditarem ser desvantajosa para seus interesses.

Tendo em vista que nossa suprema corte tem a função de guardar não só a Constituição como também os principais valores da sociedade. Daí, o conflito de proferir decisões em concordância com os princípios morais e o consentimento sobre determinado tema. Por isso, muitas vezes, a corte se reserva a opção de nada e com isso, manter a tensão entre esses valores. Surge, desse modo, o conceito de virtudes passivas que se refere aos argumentos legais utilizados para dar a oportunidade de o tribunal evitar decisões sobre esse confronto. Tal técnica, requer um profundo conhecimento e familiaridade com a arte das formas a fim de afastar-se do princípio do julgamento e inafastabilidade do Judiciário. E, deixar, portanto, essa decisão a cargo das instituições eleitorais (LIMA, GOMES e BARBOSA, 2016). 
Portanto, a potencialização da participação dos membros do poder Judiciário nos atos de governo está relacionada à consolidação das garantias constitucionais do mesmo, bem como na expansão de seu campo de atuação e das consequências para a arena política. Os fatores explicativos de tal fenômeno estão relacionados a duas dimensões analíticas: uma centrada na racionalidade dos atores políticos responsáveis e a segunda situada em momento posterior pautada pela racionalidade adotada pelos juízes. A utilização das Cortes para a proteção de interesses minoritários, se dá na tentativa da oposição de reverter derrotas parlamentares ou simplesmente, para manter assuntos intrigantes em pauta. $\mathrm{O}$ momento posterior de análise, por sua vez, concentra-se do contexto que levou os juízes a decidirem de determinada forma a situações políticas submetidas através da judicialização.

A compreensão dessa postura frente à garantia da separação dos poderes do Estado. Para interpretar esses dados empiricamente, o modelo causal, por meio de uma articulação de uma série de variáveis, premissas e equações, captura a essência de um comportamento e explica os processos intrínsecos à sua ocorrência. Daí cientistas sociais partirem da ideia de gerar implicações observáveis e então aplicar procedimentos transparentes para inferir a partir de dados se a teoria se aplica ao fenômeno social analisado. O que permite a interpretação de dados empíricos sobre os fenômenos e a explicação destes fenômenos, mediante rígidas regras de inferência. Possibilitando esclarecimentos sobre os fatores que influenciam na variação de comportamento dos órgãos judiciais (GOMES NETO, 2015).

\subsection{Análise Estatística}

Diante do exposto, objetiva-se compreender a atuação parcial do STF para se autorrestringir a fim de gerar perda de objeto para boa parte das ADIs propostas por Partidos Políticos, instituições estas tidas como aglomerações sociais que objetivam a representação da população perante o governo e que obtêm sua legitimidade para tal por meio das eleições e, consequentemente, partes indispensáveis para a efetivação da democracia no Brasil.

A partir de um levantamento amostral aleatório das ADIs propostas pelos partidos políticos, observa-se se houve ou não perda de objeto e, com isso, organiza-se uma matriz binária, baseada na ferramenta Logit, para analisar a proporção de ADIs que sofreram perda de objeto e se o partido político que protocolou, com sua posição de apoiador do governo ou não, influenciariam no modo como seriam julgadas pelo STF.

Ressalte-se que a amostra de ADIs de cada partido político a serem analisadas foi designada proporcionalmente de acordo com quantidade total impetrada por cada um. Assim, foram desconsiderados da pesquisa os partidos que não propuseram nenhuma ADI e também as ações propostas pelos chamados "diretórios dos partidos" e afins. 
Com isso, para uma análise empírica, faz-se uso do Logit que, diz respeito a um tipo de análise estatística por regressão, utilizada para predizer o resultado de uma variável dependente binária categórica, baseado em uma ou mais variáveis explicativas. Ou seja, trata-se de uma espécie de análise por regressão empregada quando a variável resposta é uma variável categórica binária (quando $\mathrm{p}$ tende a 0 , Logit(p) tende a $\infty \mathrm{e}$ quando p tende a $1, \operatorname{Logit}(\mathrm{p})$ tende a $\infty$ ), baseada na transformação logística ou Logit de uma proporção. $\mathrm{O}$ uso deste instrumento permite, portanto, saber se uma variável interfere muito, pouco ou simplesmente não interfere nas variações estatísticas do caso estudado.

Nesse sentido, a organização e sistematização dos dados, com amparo em modelos estatísticos adaptados ao estudo do comportamento judicial e tendo como base alguns modelos teóricos nesse sentido, torna-se possível uma pesquisa de como posicionamentos políticos influenciam as decisões na nossa Corte Constitucional que, em tese, deveria se manter alheia a tais questões e se ater ao seu papel para com a democracia. Do universo de 1108 ações, a amostra utilizada consistiu em 300 ADIs distribuídas proporcionalmente de acordo com a quantidade proposta por cada partido e com um intervalo de confiança de $95,15 \%$.

Tabela 1: Variáveis integrantes do modelo.

\begin{tabular}{|c|c|c|}
\hline ADI & perda de objeto(1) ou não(0) & Categórica Binária (dependente) \\
\hline Respectivo partido & partido que propôs(1) os demais $(0)$ & Categórica Binária (independente) \\
\hline
\end{tabular}

Fonte: Elaboração dos autores.

Esse trabalho fez uso da Logit ou regressão binária, que diz respeito a uma ferramenta de análise de fenômenos sociais com a codificação dos eventos em variáveis categóricas e a apresentação de resultados dicotômicos, ou seja, sucesso ou insucesso. Para as análises, classificou-se as variáveis em qualitativas nominais, formando uma matriz em que o numeral " 1 " dizia respeito à presença da categoria, enquanto que o numeral " 0 " fez referência à ausência da categoria. Assim, nesse caso baseado em uma análise logit binária, se o resultado estatístico encontrado tiver sinal positivo $(+)$, significa que a variável explicativa (independente) está associada ao aumento das chances da primeira alternativa (1) ocorrer; por outro lado, se o resultado obtido tiver sinal negativo (-), a respectiva variável explicativa estaria associada à diminuição das chances do evento (1) ocorrer; destarte, se o resultado obtido for muito próximo a 0 (zero), significa ausência de associação ou uma associação muito baixa, sem qualquer interferência nas chances de ocorrer o evento sob predição no modelo (GOMES NETO, BARBOSA, LIMA, VIEIRA, 2017). 
Gráfico 1: Representação gráfica das chances de ocorrer o evento na presença das variáveis partidárias - Coeficiente exponencial - Exp (B) - em análise estatística por regressão logística (logit).

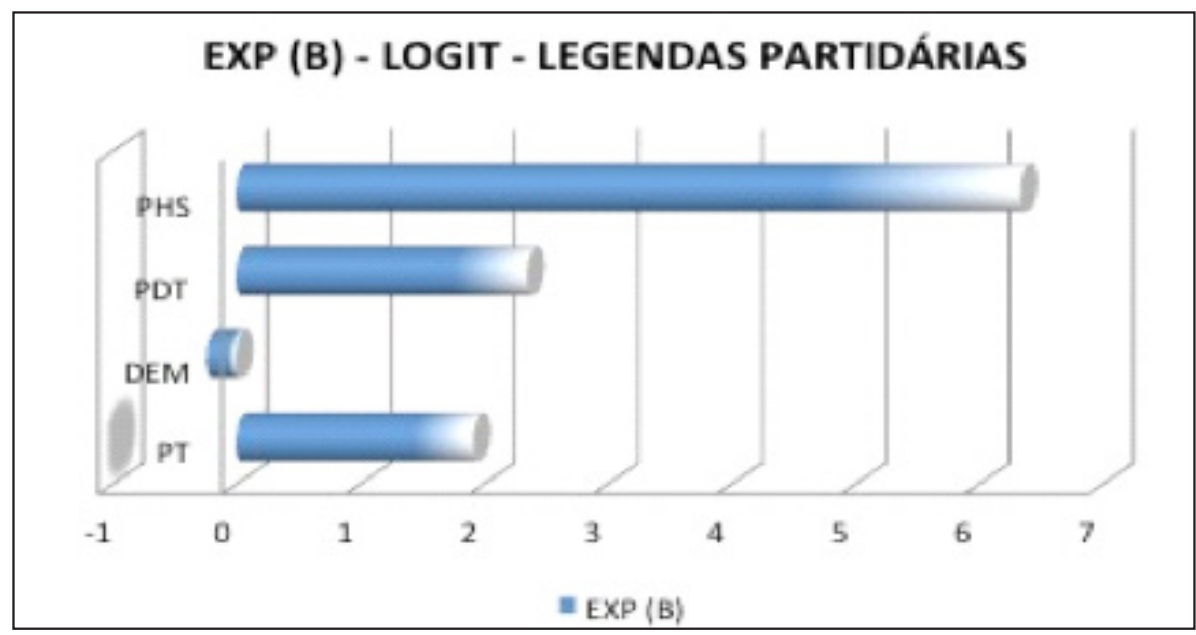

Fonte: Elaborado pelos autores.

O coeficiente exponencial utilizado no gráfico acima após uma interpretação no sentido de verificar que esta unidade de medida afere os prováveis efeitos de uma variável sobre as chances da variável dependente ocorrer. Assim, ao observar o gráfico 1, verifica-se que as chances de haver perda de objeto são em torno de seis vezes maiores para o partido político PHS do que aos demais, sendo esse um pequeno partido de centro que, no geral, propõe ADIs para ter meios de ação no cenário político uma vez que devido a sua pequena representação no congresso nacional, seus interesses por vezes não são levados em conta. Daí, a propositura dessas ações lhes garante ao menos uma tentativa de defender o que acreditam. No entanto, conforme as pesquisas mostraram, este não é um meio muito eficaz posto que são altas as chances de não obterem julgamento e a ação ser extinta por perda de objeto.

Ainda sobre esse gráfico, observam-se outros três partidos. Um de direita, o DEM e outros dois de esquerda, o PDT e o PT. O PDT, por ser também um partido pequeno, segue a mesma justificativa do PHS, porém diferencia-se no tocante a sua ideologia. Por se tratar de um partido de esquerda, juntamente com o PT, na época em que eram oposição ao governo, ou seja, antes do governo do ex-presidente Lula, um dos recursos que dispunham para mostrar sua divergência de interesses no congresso era com o uso de ADIs. O PT principalmente, já que foi o partido que mais as propôs na história, num total de 218. Mas ao assumirem a Presidência da República a proatividade nesse sentido sofreu uma queda vertiginosa.

Por fim, o DEM é o melhor exemplo de um partido de direita, ao ilustrar a grande tendência que possuíam de terem suas ações julgadas e não sofrerem perda de 
objeto, pois na época de maior propositura não eram oposição ao governo e quando passaram a sê-lo não necessitavam recorrer ao Poder Judiciário para terem suas ideias levadas em consideração por que permaneceram um partido com expressiva representação no Poder Legislativo. Com isso:

Gráfico 2: Gráfico 1: Representação gráfica das chances de ocorrer o evento na presença das variáveis ideológicas - Coeficiente exponencial - Exp (B) - em análise estatística por regressão logística (logit).

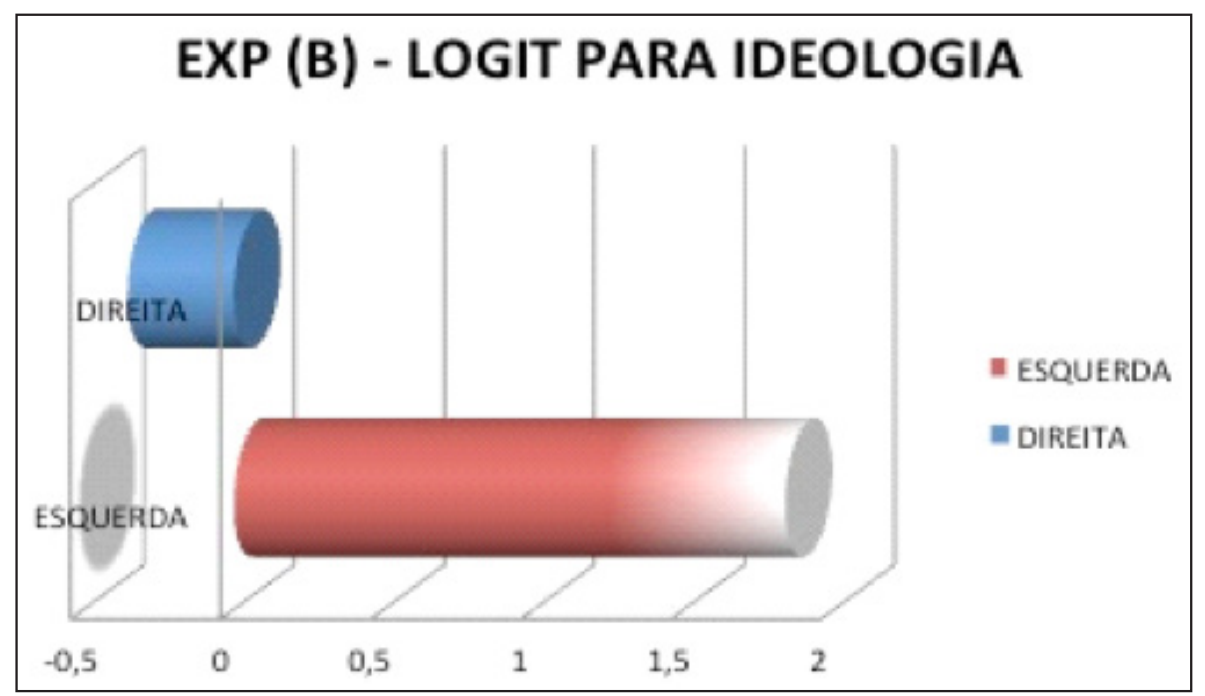

Fonte: Os autores.

Fazendo uso da mesma linha de análise utilizada para o gráfico 1, o gráfico 2 também foi elaborado com base no coeficiente exponencial. Então, pode-se extrair deste que partidos políticos com ideologia de esquerda têm, aproximadamente, duas vezes mais chance de sofrerem com a perda de objeto quando propuserem ADIs. Já os de direita possuem 0,5 mais chances de terem suas ações julgadas. Desse modo, a ideologia do partido influencia fortemente na probabilidade deste sofrer perda de objeto ou não. Isso se deve ao fato de que a maior parte das ADIs foram propostas antes do início da gestão do PT e, por isso, a ideologia predominante na Assembleia Nacional era de direita. Assim, a oposição da época tendia a recorrer ao STF para ter a apreciação dos temas que lhe interessava. A direita, contudo, ajuizava, em sua maioria, ações voltadas aos interesses da gestão e, por isso, sofriam menos com a falta de julgamento. Portanto, a ideologia partidária é um importante variável de análise que, geralmente, influencia na perda de objeto se for discordante ou oposta aos ideais governantes. 
Conforme essa pesquisa quantitativa mostrou, a hipótese inicial se confirmou já que os partidos de modo geral têm altas chances de sofrerem perda de objeto, ferindo, com isso, o processo democrático brasileiro pois ao restringir o acesso dessas organizações de representação social a um devido processo legal, diminui-se a representação de alguns segmentos populacionais. Confirmou-se também que os partidos maiores têm menos chance de terem suas ADIs extintas por perda de objeto visto que o arranjo político faz com que possam defender seus interesses no Congresso Nacional e utilizarem o STF apenas ocasionalmente e para assuntos, no geral, aliados e defensores do governo, enquanto que os partidos menores, por possuírem uma ínfima representação na Assembleia Nacional, têm que fazer uso dessas ações para colocarem seus objetivos à vista, o que, consequentemente, na maioria dos casos, não interessa à gestão.

A ideologia partidária, por sua vez, também influencia fortemente na ocorrência ou não da perda de objeto, posto que os partidos da oposição têm grandes chances de sofrê-la enquanto que os partidos aliados ao governo, por outro lado, têm maiores chances estatísticas de julgamento de suas ações. Ressalte-se ainda que as denominações de esquerda, direita, centro etc. interferem somente no tocante ao posicionamento do partido frente ao governo no momento de propositura da ADIN.

\section{Conclusão}

Frequentemente, partidos políticos cujos interesses e preferências foram derrotados no campo legislativo decidem por judicializar tais questões e submeter à nossa Corte Suprema avaliação de constitucionalidade de leis e de outros atos normativos, aprovados ao arrepio das preferências das legendas proponentes.

Como se comporta o Supremo Tribunal Federal quando instado a julgar ações diretas de inconstitucionalidade propostas por partidos políticos? Em regra, consistem em litígios com altos custos decisórios, principalmente custos políticos e sociais, em resposta aos quais o Tribunal reage com forte postura autorrestrita, principalmente mediante a utilização da estratégia silenciosa do prejuízo pela perda superveniente do objeto, em que questões controversas aguardam por longos períodos, sem qualquer pronunciamento judicial quanto à alegada inconstitucionalidade.

Este artigo avança na compreensão do comportamento decisório, no caso, o comportamento autorrestrito do Supremo Tribunal Federal, quando provocado a resolver conflitos instaurados judicialmente pelos partidos políticos, identificando padrões de decisão, no tocante ao tamanho dos partidos; ao seu posicionamento dentro do Parlamento (situação ou oposição); e ao seu viés ideológico e como esses fatores influenciam as chances de sofrerem com perda de objeto. Ao fazer uso de uma regressão logística binária, tendo como variável dependente a perda ou não de objeto e como variável independente os respectivos partidos que propuseram as $300 \mathrm{ADIs}$ que compuseram a amostra utilizada, é possível observar que partidos políticos, em geral, têm grandes chances de sofrerem perda de objeto. 
Verifica-se também que partidos maiores têm menos chance de corresponder à hipótese inicial, visto que, matematicamente, grande parte se suas ações são julgadas. Constatou-se, por fim, que a ideologia partidária influencia muito a perda de objeto, uma vez que os partidos de oposição ao governo, conforme mostraram os resultados da regressão, tendem a sofrê-la enquanto que os partidos aliados ao governo no momento de propositura das ações obtêm julgamentos.

A análise empírica quantitativa realizada neste estudo descobriu interessantes padrões comportamentais da Corte em relação às demandas ajuizadas pelos partidos políticos, que nos auxiliam na compreensão das interações entre as instituições partidárias e os órgãos judiciais, mostrando razões de seletividade quanto a intervir, ou não, em questões já deliberadas na arena legislativa, evitando, em muitos pontos, influir na lógica democrática. 


\section{Referências}

BARROSO, Luís Roberto. Curso de Direito Constitucional Contemporâneo: Os conceitos fundamentos e a construção do novo modelo. 4. ed. São Paulo: Saraiva, 2013.

BENEVIDES, Maria Victoria de Mesquita. A cidadania Activa-Referendo, Plebiscito e iniciativa popular. São Paulo. Ed. Ática, 1991.

BOBBIO, Norberto. Estado, governo, sociedade. São Paulo: Paz e Terra, 1987.

BONAVIDES, Paulo. Ciência política. 10. ed. São Paulo: Malheiros, 2003.

CARVALHO, Ernani Rodrigues de. Revisão Judicial e Judicialização da Política no Direito Ocidental: Aspectos Relevantes de sua Gênese e Desenvolvimento. Revista de Sociologia e Política, v. 28, p. 161-179, 2007.

CARVALHO, Ernani Rodrigues de. O Supremo Tribunal Federal: das trincheiras de defesa dos direitos individuais ao processo decisório do Estado. In: Sérgio Praça; Simone Diniz. (Org.). Vinte anos de Constituição. São Paulo: Paulus, v., p. 77-94, 2008.

CHRIS GIDLOW (Inglaterra). The really useful guide to Kings and Queens of England. Surrey: Historic Royal Palaces, 2013.

DAHL, Robert. Poliarquia: participação e oposição. São Paulo: Edusp, 1997.

GOMES, José Jairo. Direito Eleitoral. 9. ed. São Paulo: Atlas, 2013.

GOMES, José Mário W.; BARBOSA, Luís Felipe A.; LIMA, Flávia Santiago; VIEIRA, Jorge Luiz G.: Explicando Decisões: As Aplicações da Análise por Regressão Logística (Logit) no Estudo do Comportamento Judicial. (paper ainda não publicado, 2017).

https://creartehistoria.blogspot.com.br/2013/06/el-imperialismo-en-mapas.html (acesso em 28/04/2017, às 16h)

HELLFELD, Matthias Von.; Revolução Gloriosa marcou início da democracia parlamentar europeia, DW, 2009.

HELMKE, Gretchen. Enduring Uncertainty: Court-Executive relations in Argentina During the 1990s and Beyond. In: LEVITSKY, Steven; MURILLO, Maria Victoria (ed.) Argentine Democracy: The Politics of Institutional weakness. University Park, Pennsylvania: The Pennsylvania University Press, 2002.

INGLATERRA. ANDREW FESTING. The Palace of Westminster: Official Guide. London: Houses Of Parliament, 2016.

JACKSON, Robert; SORENSEN, Georg. Introdução às Relações Internacionais. 2. ed. Rio de Janeiro: Zahar, 2013.

JALALI, Carlos. Partidos e sistemas partidários. Lisboa: Fundação Francisco Manuel dos Santos, 2017. 
KANT, Immanuel. A Paz Perpétua: Um Projecto Filosófico. Covilhã: Lusosofia, 2008. KELLY, Paul et al. O Livro da Política. São Paulo: Globo, 2013.

LENZA, Pedro. Direito constitucional esquematizado. 13. ed. São Paulo: Saraiva, 2009.

LIMA, Flávia Santiago; GOMES, José Mário W.; Barbosa, Leon Victor Q. Exploring The Wonderful Mystery of Time: "Lack of Grounds" in the Constitucional Judicial Review as an Evidence of Passive Virtues in the Brazilian Supreme Court (STF); IPSA; Poznan, Poland, 2016.

MENDONÇA, Otávio. Partidos políticos brasileiros. Revista de Informação Legislativa, Rio de Janeiro, v. 17, n. 68, p.145-156, nov. 1980. Disponível em: <http:// www2.senado.leg.br/bdsf/handle/id/181227>. Acesso em: 28 ago. 2017.

MESQUITA JÚNIOR, Geraldo; Os filósofos da política: iluminismo, a filosofia da ilustração. Senado Federal, 2004.

MINGST, Karen. Princípios de Relações Internacionais. 4. ed. Rio de Janeiro: Elsevier, 2009.

MORAES, Alexandre de. Direito Constitucional. 23. ed. São Paulo: Atlas, 2008.

OLIVEIRA, Maria Marly de. Como Fazer: projetos, relatórios, monografias, dissertações e teses. 3. ed. Rio de Janeiro: Elsevier, 2005.

PARKER, Michael St John. Life in Georgian Britain. Hampshire: Pitkin, 2011.

PARKER, Michael St John. Life in Victorian Britain. Gloucestershire: Pitkin, 2013.

POSNER. The meaning of judicial self-restraint. Indiana Law Journal, vol.59, n.1, p.124, 1983.

POSNER, Richard. How judges think. Cambridge: Havard University Press, 2008.

PRZEWORSKI, Adam., "Ama a Incerteza e Serás Democrático". Novos Estudos Cebrap, n. 9, p. 36-46, 1984.

SEGAL, Jeffrey A.; SPAETH, Harold J. The Supreme Court and the attitudinal model revisited. Cambridge: Cambridge University Press, 2002.

SCHUMPETER, Joseph. Capitalismo, Socialismo e Democracia. Nova Iorque: Harper \& Brothers, 1942.

SUSTEIN, Cass R. Designing Democracy: What Constitutions do. Oxford, Oxford University Press, 2001.

SUSTEIN, Cass R.; SCHKADE, David; ELLMAN, Lisa M.; SAWICKI, Andres. Are Judges Political? An empirical analysis of Federal Judiciary. Washington DC: Brookings Institution Press, 2006. 
TAROUCO, Gabriela da Silva; MADEIRA, Rafael Machado: partidos, programas e o debate sobre esquerda e direita no brasil. Revista de sociologia e política v. $21, \mathrm{n}^{\circ} 45$ : 149-165 mar. 2013.

TATE, C. Neal; VALLINDER, Torbjörn. The global expansion of judicial power. New York: New York University Press, 1995.

TAYLOR, Matthew. Judging policy: Courts and Policy Reform in Democratic Brazil. Stanford: Stanford University Press, 2008.

TAYLOR, Matthew M. Veto and Voice for the Courts: Policy Implications of Institutional Design in the Brazilian Judiciary, 2004.

TAYLOR, Matthew M. Citizens against the state: the riddle of high impact, low functionality courts in Brazil. Brazilian Journal of Political Economy, vol.25, n.4 (100), October-December, 2005.

TAYLOR, Matthew M; DA ROS, Luciano. Os partidos dentro e fora do poder: judicialização como resultado contingente da estratégia política. Revista Brasileira de Ciências Sociais, Rio de Janeiro, vol. 51, n.4, p.825-864, 2008.

THÉBAULT, Vincent et al (Ed.). Géopolitique de l'Europe. 4. ed. Paris: Nathan, 2014

WERNECK VIANNA, Luiz; CARVALHO, Maria Alice Rezende; MELO, Manuel; Palácios Cunha; BURGOS, Marcelo Baummam. A Judicialização da Política e das Relações Sociais no Brasil. Rio de Janeiro: Revan, 1999.

WILLIAMSON, David. Kings and Queens: National Portrait Gallery. 4. ed. London: National Gallery Publications, 2013. 